\title{
INTERFERÊNCIA DE Cenchrus echinatus NO CRESCIMENTO INICIAL DO ALGODOEIRO
}

\author{
PELLOSI, Fabio Soares ${ }^{1}$ \\ ROMANCINI, Mateus Landin ${ }^{1}$ \\ PAULA, Vitor Thomé de ${ }^{1}$ \\ PIRRI, Marcus ${ }^{1}$ \\ OLIVEIRA, Welton Dias de ${ }^{1}$ \\ SANTOS, Leticia Serpa dos ${ }^{1}$ \\ ZERA, Fabrício Simone ${ }^{1}$
}

\begin{abstract}
RESUMO: O Cenchrus echinatus é uma planta daninha importante para o cultivo do algodoeiro, tanto no início do cultivo como no final, trazendo prejuízos ao produto. $\mathrm{O}$ objetivo do trabalho consistiu em avaliar a interferência de plantas de C. echinatus, popularmente conhecida como capim-carrapicho, no crescimento inicial do algodoeiro. $\mathrm{O}$ experimento foi instalado em casa de vegetação, em delineamento experimental inteiramente casualizado, sendo as parcelas compostas por vasos de cinco litros. Os tratamentos foram constituídos com $0,1,2,4$ e 8 plantas de $C$. echinatus em competição com uma planta de algodão por vaso. Os parâmetros avaliados foram a altura e diâmetro do caule das plantas de algodão aos 17, 25, 32 e 38 dias após a semeadura (DAS), e a massa seca das plantas de algodão aos 38 DAS. A presença, a partir de uma planta de capim-carrapicho, compromete o desenvolvimento da planta de algodão a partir dos 32 DAS, em altura, diâmetro do caule e massa seca da parte aérea. Concluiu-se que o $C$. echinatus interferiu no desenvolvimento inicial do algodoeiro em altura, diâmetro e massa seca das plantas até aos 38 DAS.
\end{abstract}

Palavras-chave: Gossypium hirsutum L. Capim-carrapicho. Matocompetição.

SUMMARY: Cenchrus echinatus is a weed of great importance for the Cotton cultivation, as much at the beginning of the seedling as at the end of the cultivation, causing damages in the product. Therefore, the objective of this study is evaluating the interference of $C$. echinatus plants, popularly known as grass-burr, in the initial growth of cotton. The trial was installed in a greenhouse, in a completely randomized experimental design, the plots were composed of five-liter vessels. The treatments were $0,1,2,4$ and 8 plants of $C$. echinatus in competition with a cotton plant per pot. The parameters evaluated were the height and diameter of the stem of the cotton plants at 17, 25, 32 and 38 days after sowing (DAS), and the dry mass of the cotton plants at 38 DAS. The presence of grasshopper with cotton from a plant compromises the development of the cotton plant from the 32 DAS, height, diameter and dry mass of the cotton plants. It was concluded that $C$. echinatus interfered in the initial development of the cotton in the height, diameter and dry mass of the plants up to 38 DAS.

Keywords: Gossypium hirsutum L. Grass-burr. Weed competition.

\section{INTRODUCÃO}

O algodão (Gossypium hirsutum L. raça latifolium Hutch.) é uma cultura importante no setor agrícola brasileiro, em termos de área plantada fica em quinto lugar, perdendo para as culturas de soja, milho, feijão e arroz. Os principais estados produtores são, Mato Grosso, Bahia, Goiás, Minas Gerais, Mato Grosso do Sul e Maranhão. A produção brasileira de algodão, estimada para a safra 2018/19, é de 2,72 milhões de toneladas de pluma, isso significa um aumento de 35,9\% em relação ao produzido na safra anterior, que foi de 2.005,8 mil toneladas. A queda na produtividade, em relação à safra anterior, é

\footnotetext{
${ }^{1}$ Instituto Taquaritinguense de Ensino Superior - ITES - Taquaritinga, SP. - Instituto Taquaritinguense de Ensino Superior - ITES - Taquaritinga, SP.
} 
estimada em 1,3\%. Já a expansão da área plantada foi de 37,8\%, atingindo 1,61 milhão de hectares. (CONAB, 2019).

Segundo a Conab (2019) em relação à produção internacional, o destaque é para os Estados Unidos (a safra desse país deve ser a maior em 15 anos) e para a Índia, que vão majorar suas produções em 22,5\% e 9,4\%, respectivamente. Quanto ao consumo, é importante salientar o crescimento de China, Vietnam e Bangladesh. Pelo fato desses três serem os principais importadores mundiais, o aquecimento de suas demandas poderá amenizar, em parte, o viés de baixa no segundo semestre de 2019.

Apesar do decréscimo nos últimos anos e acréscimo na produtividade, a cultura do algodão é bastante considerada para o futuro, em se tratando de médio prazo, seja em tecnologias de plantio, manejo da cultivar durante seu estágio vegetativo, colheita e pós colheita, considerando que o algodoeiro tem inúmeras peculiaridades, fragilidades e cuidados na sua condução até chegar às mãos dos clientes finais.

Pode-se citar o caso de algumas plantas daninhas com poder de interferir, desde a semeadura, e danificar a fibra do algodão, como é o caso do capim-carrapicho. As exigências nutricionais afetam o crescimento vegetativo da planta, e, seus espinhos podem comprometer a produção de fibras de algodão, fazendo com que seu valor comercial caia drasticamente.

Em geral, as plantas daninhas interferem na produtividade do algodoeiro, assim como em todas as plantas cultivadas, com o agravante de que, o algodão, tem crescimento lento, até 45 dias após a emergência, enquanto as plantas daninhas tem um crescimento rápido durante esse período, sobressaindo e apresentando vantagens sobre o algodão (BORÉM; FREIRE, 2014). O período crítico da convivência do algodoeiro com plantas daninhas está entre 8 e 66 dias após a emergência da cultura, e, em lavouras sem nenhum controle durante esse período, a produtividade pode ser reduzida em até 97\% (SALGADO et al., 2002).

A semeadura do algodão normalmente ocorre em novembro e sua colheita de abril a junho, o que coincide exatamente com a ocorrência do capim-carrapicho. Sua aparição se dá no verão, podendo ser de outubro até abril. Isso pode resultar em interferência desde a semeadura até a colheita, sendo encontrado o carrapicho até em fibras do algodão, após a colheita, desvalorizando o produto. (FONTES, 2003).

O manejo de plantas daninhas no algodoeiro deve ser eficaz durante todo seu ciclo, em primeiro momento devido ao seu crescimento lento, e em segundo porque deve-se realizar um controle eficaz até a colheita. Isso ocorre porque a presença de plantas daninhas no momento da colheita, atrapalha não só a colheita de forma geral, mas também compromete o produto final, a pluma. Isso ocorre devido algumas espécies de plantas daninhas que tem estruturas na semente de fixação para dispersão como Cenchrus echinatus (capim-carrapicho) e Bidens pilosa (picão-preto). As sementes destas espécies de plantas daninhas se fixam na pluma de forma irreversível, desvalorizando o produto final (BORÉM; FREIRE, 2014).

O C. echinatus é uma das espécies de plantas daninhas mais comum no cerrado brasileiro e no cultivo do algodoeiro (FERREIRA; BARROS; LAMAS, 2006). Em condições favoráveis a partir de 48 dias após a semeadura o C. echinatus já floresce, mostrando seu alto potencial (MACHADO, 2013).

A escolha do C. echinatus ocorreu por ser uma planta daninha de suma importância para o cultivo do algodoeiro, tanto no início do cultivo como no final, trazendo prejuízos no produto. Sendo assim, o objetivo do trabalho consistiu em avaliar a interferência de plantas de C. echinatus, popularmente conhecida como capim-carrapicho, no crescimento inicial do algodoeiro.

\section{MATERIAL E MÉTODO}

O experimento foi conduzido em ambiente aberto, com localização $-21^{\circ} 40^{\prime} 79^{\prime}$ ' S e $-48^{\circ} 50^{\prime} 05^{\prime \prime} \mathrm{O}$, 
com $548 \mathrm{~m}$ de altitude. Foi utilizado o delineamento inteiramente casualizado, testando cinco densidades de $C$. echinatus $(0,1,2,4,8$ plantas por vaso, que correspondem aproximadamente a $0,6,11,22$ e 44 plantas por $\mathrm{m}^{2}$ ) com cinco repetições, totalizando 25 parcelas. Cada parcela foi composta por um vaso de polietileno com capacidade de $5 \mathrm{dm}^{3}$.

Primeiramente todos os vasos foram preenchidos com solo de textura arenosa com as seguintes características: $\mathrm{pH}\left(\mathrm{CaCl}_{2}\right)$ de 4,3; $40 \mathrm{~g} \mathrm{dm}^{-3}$ de matéria orgânica e teores de $\mathrm{P}=41 ; \mathrm{K}^{+}=0,9 ; \mathrm{Ca}^{2+}=13,0$; $\mathrm{Mg}^{2+}=7,0$ e CTC $=93,7$ expressos em mmolc $\mathrm{dm}^{-3}$. No preenchimento o solo foi corrigido e adubado conforme recomendação de Espironelo et al. (1995), de modo a atender as necessidades nutricionais do algodão.

A semeadura ocorreu em 29 de setembro de 2018, utilizando sementes de algodão da cultivar TMG 47 B2RF. Foram semeadas cinco sementes por vaso e após a emergência foram desbastadas, deixando uma planta de algodão por vaso. Simultaneamente as sementes de C. echinatus também foram semeadas nos vasos. Para atingir a densidade de plantas daninhas, foram semeadas vinte sementes e após a emergência deixou permanecer somente o numero de plantas de C. echinatus referente a cada tratamento.

Aos 17, 25, 32 e 38 dias após a semeadura (DAS) foram avaliados a altura e o diâmetro das plantas de algodão. A altura foi medida pelo comprimento da planta desde o solo até a inserção da última folha com o auxilio de uma régua e o diâmetro foi medido no terço médio do caule das plantas com um paquímetro.

Aos 38 DAS foi determinada a biomassa seca das plantas de algodão de cada tratamento. A planta foi coletada, identificada em sacos de papel, inserido em estufa de secagem com circulação forçada de ar, com temperatura constante de $70^{\circ} \mathrm{C}$ durante o período de noventa e seis horas, após as amostras estarem secas, com auxílio de balança de precisão obteve-se a massa seca das amostras.

Os dados obtidos foram submetidos à análise de variância pelo teste $\mathrm{F}(\mathrm{p}<0,05)$ e as médias comparadas pelo teste de Tukey a 5\% utilizando o programa AgroEstat (BARBOSA; MALDONADO, 2015). Para a biomassa seca, quando houve diferença significativa entre os tratamentos, utilizou-se também analise de regressão polinomial.

\section{RESULTADO E DISCUSSÃO}

Na avaliação de altura das plantas de algodão não houve diferença significativa entre todos os tratamentos nas duas primeiras avaliações, aos 17 e 25 DAS. Aos 32 DAS verificou-se diferença entre os tratamentos (Tabela 1). A maior altura foi observada no Tratamento $\mathrm{T} 1$, sem competição com $C$. echinatus., que diferiu apenas do T5 (oito plantas por vaso), que apresentou a menor média, $11 \mathrm{~cm}$. Aos 38 DAS a maior altura foi observada no T1, com 15,80 cm de altura, que diferiu do T3 (com duas plantas daninha por vaso), T4 (com quatro plantas daninhas por vaso) e T5 (com oito plantas daninha por vaso), $11,60 \mathrm{~cm}, 11,00 \mathrm{~cm}$ e $10,40 \mathrm{~cm}$, respectivamente. O T2 não diferiu dos demais tratamentos. Zera et al (2016) verificaram que a Urochloa plantaginea, Sida rhombifolia, Digitaria horizontalis e Panicum maximum interferiu na altura de mudas pré-brotadas de cana, cv IACSP95-5000, até aos 30 dias após o plantio das mudas, com 8 plantas por vaso. 
Tabela 1 - Altura, em cm, das plantas de algodão em competição com C. echinatus aos 17, 25, 32 e 38 DAS. Taquaritinga, 2019.

\begin{tabular}{|c|c|c|c|c|}
\hline \multirow{2}{*}{ Tratamentos } & \multicolumn{4}{|c|}{ Altura } \\
\hline & 17 DAS & 25 DAS & 32 DAS & 38 DAS \\
\hline T1 - 0 pl C. echinatus vaso ${ }^{-1}$ & $9,20 \mathrm{a}$ & $12,20 \mathrm{a}$ & $14,40 \mathrm{a}$ & $15,80 \mathrm{a}$ \\
\hline $\mathrm{T} 2-1 \mathrm{pl} \mathrm{C.} \mathrm{echinatus}$ vaso $^{-1}$ & $8,40 \mathrm{a}$ & $11,40 \mathrm{a}$ & $13,00 \mathrm{ab}$ & $13,20 \mathrm{ab}$ \\
\hline $\mathrm{T} 3-2 \mathrm{pl}$ C. echinatus vaso ${ }^{-1}$ & $8,60 \mathrm{a}$ & $11,20 \mathrm{a}$ & $12,00 \mathrm{ab}$ & $11,60 \mathrm{~b}$ \\
\hline $\mathrm{T} 4-4 \mathrm{pl} \mathrm{C.} \mathrm{echinatus}$ vaso $^{-1}$ & $8,40 \mathrm{a}$ & $10,20 \mathrm{a}$ & $11,20 \mathrm{ab}$ & $11,00 \mathrm{~b}$ \\
\hline T5 $-8 \mathrm{pl}$ C. echinatus vaso ${ }^{-1}$ & $7,80 \mathrm{a}$ & $10,00 \mathrm{a}$ & $11,00 \mathrm{~b}$ & $10,40 \mathrm{~b}$ \\
\hline $\mathrm{F}$ & $0,58^{\mathrm{NS}}$ & $1,80^{\mathrm{NS}}$ & $3,18^{*}$ & $6,53 * *$ \\
\hline $\mathrm{CV}(\%)$ & 17,33 & 13,72 & 14,29 & 15,30 \\
\hline
\end{tabular}

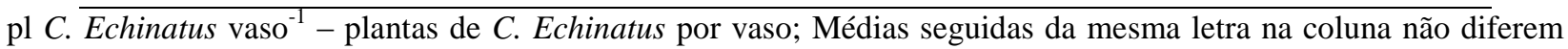
entre si pelo teste de Tukey $(\mathrm{p}<0,05) ; \mathrm{CV}(\%)=$ coeficiente de variação; $\mathrm{NS}=$ não significativo; $* * \mathrm{e}^{*}=$ significativo a 1 e $5 \%$, respectivamente.

Quanto ao diâmetro das plantas de algodão não foram verificadas diferenças significativas nas duas primeiras avaliações, aos 17 e 25 DAS (Tabela 2). Aos 32 DAS, o maior diâmetro foi observado no T1 (sem plantas de C. echinatus por vaso), que diferiu do T4 e T5, respectivamente com quatro e oito plantas de $C$. echinatus por vaso. O T2 e o T3, com uma e duas plantas de $C$. echinatus, não se diferenciaram aos 32 DAS dos demais tratamentos. Aos 38 DAS, o maior diâmetro foi observado no T1 $(5,20 \mathrm{~mm})$, que diferiu do T3, T4 e T5 (4,00; 3,80 e 3,20 mm; respectivamente). O T2 (4,60 mm) não diferiu do T1, T3 e T4 (5,20; 4,00 e 3,80 mm; respectivamente). Os tratamentos T3 e T4 (4,00 e 3,80 mm; respectivamente) não deferiu dos tratamentos T2 e T5 (4,60 e 3,20 mm; respectivamente), porém o menor diâmetro foi observado no T5 com 3,20 mm.

Tabela 2 - Diâmetro, em mm, do caule das plantas de algodão em competição com plantas de $C$. echinatus aos 17, 25, 32 e 38 dias após a semeadura. Taquaritinga, 2019.

\begin{tabular}{|c|c|c|c|c|}
\hline \multirow{2}{*}{ Tratamentos } & \multicolumn{4}{|c|}{ Diâmetro } \\
\hline & 17 DAS & 25 DAS & 32 DAS & 38 DAS \\
\hline T1 - 0 pl C. echinatus vaso ${ }^{-1}$ & $2,40 \mathrm{a}$ & $3,40 \mathrm{a}$ & $4,20 \mathrm{a}$ & $5,20 \mathrm{a}$ \\
\hline $\mathrm{T} 2-1 \mathrm{pl}$ C. echinatus vaso $^{-1}$ & $2,00 \mathrm{a}$ & $3,40 \mathrm{a}$ & $3,80 \mathrm{ab}$ & $4,60 \mathrm{ab}$ \\
\hline T3 -2 pl C. echinatus vaso ${ }^{-1}$ & $2,00 \mathrm{a}$ & $3,20 \mathrm{a}$ & $3,60 \mathrm{ab}$ & $4,00 \mathrm{bc}$ \\
\hline $\mathrm{T} 4-4 \mathrm{pl}$ C. echinatus vaso $^{-1}$ & $2,00 \mathrm{a}$ & $3,00 \mathrm{a}$ & $3,20 \mathrm{~b}$ & $3,80 \mathrm{bc}$ \\
\hline T5 $-8 \mathrm{pl}$ C. echinatus vaso ${ }^{-1}$ & $2,00 \mathrm{a}$ & $2,80 \mathrm{a}$ & $3,20 \mathrm{~b}$ & $3,20 \mathrm{c}$ \\
\hline $\mathrm{F}$ & $2,67^{\mathrm{NS}}$ & $1,70^{\mathrm{NS}}$ & $4,09 *$ & $7,74 * *$ \\
\hline $\mathrm{CV}(\%)$ & 11,78 & 14,15 & 13,03 & 14,82 \\
\hline
\end{tabular}

pl C. Echinatus vaso $^{-1}$ - plantas de C. Echinatus por vaso; Médias seguidas da mesma letra na coluna não diferem entre si pelo teste de Tukey $(\mathrm{p}<0,05) ; \mathrm{CV}(\%)=$ coeficiente de variação; $\mathrm{NS}=$ não significativo; $* *$ e $*=$ significativo a 1 e $5 \%$, respectivamente.

Tartaglia (2017) ao estudar a competição intraespecífica e densidade da população de plantas daninhas em geral, no crescimento do algodão, observou que ao aumentar a população de plantas daninhas 
reduziu o crescimento do caule das plantas de algodão, assim como neste trabalho que foi observado menor diâmetro do caule com o aumento da população de capim-carrapicho a partir de 32 DAS.

A massa seca das plantas de algodão realizado aos 38 DAS obteve diferença entre os tratamentos (figura 1). O T1 obteve as plantas com maior média da massa seca, com 1,50 g, que deferiu do T3, T4 e T5 (0,79; 0,64 e 0,45 g; respectivamente). O T2 (1,12 g) não deferiu do T1 (1,50 g), T3 (0,79 g) e T4 (0,64 g). O T3 $(0,79 \mathrm{~g})$ e T4 $(0,64 \mathrm{~g})$ não deferiu do T2 $(1,12 \mathrm{~g})$ e T5 $(0,45 \mathrm{~g})$. A menor média da massa seca foi observada no T5 com $0,45 \mathrm{~g}$, o que registra o menor diâmetro e altura das plantas de algodão quando elas foram submetidas a competição de 8 plantas de C. echinatus por vaso.

Figura 1 - Massa seca, em gramas, das plantas de algodão em competição com C. echinatus aos 38 DAS. Taquaritinga, 2019.

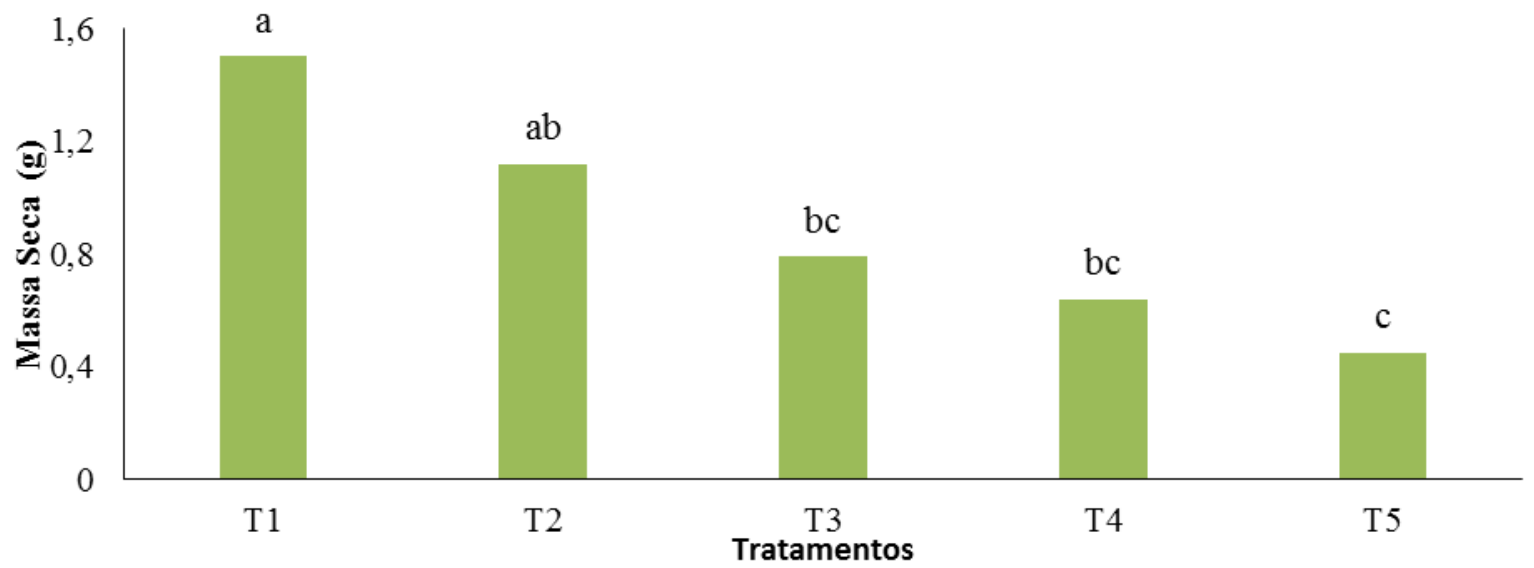

T1 - 0 pantla de C. echinatus vaso ${ }^{-1}, \mathrm{~T} 2$ - 1 plantas de C. echinatus vaso $^{-1}, \mathrm{~T} 3$ - 2 plantas de $C$. echinatus vaso $^{-1}, \mathrm{~T} 4$ 4 plantas de $C$. echinatus vaso ${ }^{-1}$, T5 -8 plantas de C. echinatus vaso $^{-1}$; Médias $=\mathrm{T} 1=1,50 \mathrm{~g} ; \mathrm{T} 2=1,12 \mathrm{~g} ; \mathrm{T} 3=0,79 \mathrm{~g}$; $\mathrm{T} 4=0,64 \mathrm{~g} ; \mathrm{T} 5=0,45 \mathrm{~g}$; médias seguidas da mesma letra na coluna não diferem entre si pelo teste de Tukey $(\mathrm{p}<0,05) ; \mathrm{CV}(\%)=$ coeficiente de variação; $* * *$ significativo a $1 \%$.

Salgado, Alves e Rossi (2002), ao estudar a interferência de tubérculos de (Cyperus rotundus) tiririca sobre o crescimento inicial de plantas de algodão, observaram que a tiririca interferiu no tamanho das plantas de algodão e na massa seca das plantas, assim como foi observado neste trabalho. No mesmo estudo foi avaliado a interferência da tiririca na área foliar do algodão, e foi observado que este foi o parâmetro em que as plantas de tiririca mais afetaram negativamente as plantas de algodão.

Com o estudo de período de interferência das plantas daninhas na cultura do algodoeiro, Salgado et al. (2002), observou que a partir de 14 dias após a emergência o C. echinatus apresentou dominância sobre a cultura, afetando a produtividade e o acumulo de massa seca das plantas de algodão, assim como neste trabalho que foi observado a interferência no acumulo de massa seca das plantas de algodão a partir de uma planta por vaso, a partir dos 32 DAS.

Kawaguchi, Alves e Orsi Junior (1995) verificaram que a cultura do algodão cv. IAC 20, em Jaboticabal, necessitou ficar 28 dias após a semeadura livre da interferência da comunidade infestante (PAI), com predominância de caruru, carrapicho-de-carneiro e capim-carrapicho, para que não ocorressem prejuízos qualitativos e quantitativos em sua produção. Em revisão feita por Furuhashi (1999), citando 11 trabalhos com essa cultura, o PAI variou de 10 a 40 dias, enquanto o PTPI variou de 35 a 60 dias.

Estudando a relação entre tiririca (Cyperus rotundus) e algodão, Blanco e Blanco (1991) verificaram que populações que emergem no solo após seis semanas do plantio do algodoeiro não causam prejuízos à planta cultivada. Os autores observaram que, quanto maior foi o número de tubérculos por 
área, menores foram os pesos da matéria fresca e seca das maçãs, as folhas, o caule e a altura das plantas de algodão. Densidades populacionais a partir de um tubérculo por $0,141 \mathrm{~m}^{2}$ provocaram diminuições significativas e lineares no desenvolvimento e na produção de plantas de algodão.

O que pode explicar este fato é a competição entre as plantas de C. echinatus com as plantas de algodão por água, luz e nutrientes, já que as plantas de algodão têm crescimento inicial lento o que é uma desvantagem desta em competição com outras plantas.

\section{CONCLUSÃO}

Concluiu-se que o C. echinatus interferiu no desenvolvimento inicial do algodoeiro em altura, diâmetro e massa seca das plantas até aos 38 DAS.

\section{REFERÊNCIAS}

BARBOSA, J.C.; MALDONADO Jr., W. AgroEstat: sistema para análises estatísticas de ensaios agronômicos. Versão 1.0. Jaboticabal: Departamento de Ciências Exatas, 2015.

BORÉM, A.; FREIRE, E. C. Algodão: do plantio à colheita. Viçosa: UFV, 2014.

BLANCO, H.G.; BLANCO, F.M.G. Efeito do manejo do solo na emergência das plantas daninhas. Pesquisa Agropecuária Brasileira, v.26, n.2, 1991.

COMPANHIA NACIONAL DE ABASTECIMENTO. Acompanhamento da safra brasileira: grãos, Decimo Segundo levantamento, v. 6 - Safra2018/19, n. 12 - setembro/2019 - Companhia Nacional de Abastecimento. - Brasília: Conab 2019.

FERREIRA, A.C., BARROS, A.C., LAMAS, F.M. Manejo de plantas daninhas na cultura do algodoeiro. Embrapa, ago. 2006. . (Circular Técnica, 96).

FONTES, J.R.A. Manejo integrado de plantas daninhas. Planaltina, DF: Embrapa Cerrados, 2003.

FURUHASHI, S. Combinação de herbicidas aplicados em PPI, Pré e em Pós-emergência na cultura do algodão (Gossypium hirsutum L.). Jaboticabal: UNESP, 1999.. Dissertação (Mestrado em Produção Vegetal) - Universidade Estadual Paulista, Jaboticabal, 1999.

KAWAGUCHI, I. T.; ALVES, P. L. C. A.; ORSI JÚNIOR., F. Comportamento do herbicida sulfentrazone no controle de uma comunidade infestante na cultura da cana-de-açúcar (Saccharum spp). In: Congresso Brasileiro da Ciência das Plantas Daninhas,20., Florianópolis. Resumos, 1995.

MACHADO, E.C. Crescimento e desenvolvimento do capim-carrapicho (Cenchrus echinatus). Machado, MG: Editora, 2013.

SALGADO, T.P. et al . Períodos de interferência das plantas daninhas na cultura do algodoeiro (Gossypium hirsutum). Planta daninha, Viçosa, v. 20, n. 3, p. 373-379, 2002.

SALGADO, T.P., ALVES, P., ROSSI, C. Efeito da densidade de tubérculos de Tiririca (Cyperus Rotundus) sobre o crescimento inicial de plantas de algodão. Jaboticabal, Planta Daninha, Viçosa-MG, v.20, n.3, p.405-411, 2002. 
TARTAGLIA, F. L. Crescimento, produtividade e qualidade de fibra de algodão colorido influenciados pela população de plantas. Revista Ceres, Viçosa, MG, v. 64, n.1, p. 068-076. 2017.

ZERA, et al. Interferência de plantas daninhas em mudas pré-brotadas (MPB) de cana-de-açúcar nas tecnologias Plene PB, Plene Evolve e MPB-IAC. Stab, Piracicaba, SP, v. 34, n. 5, p. 40-42. 2016. 